\title{
A Perspective on the Development of Entrepreneurial Engineering
}

\author{
* Irfaan A. Khota, ** Leon Pretorius \\ * Post Graduate Student, Rand Afrikaans University - Faculty of Engineering, Transtel \\ ** Professor, Rand Afrikaans University - Faculty of Engineering
}

\begin{abstract}
Eleven engineers working within a corporate environment and four engineers operating their own engineering businesses within a South African context were each given questionnaires which aimed at assessing their entrepreneurial orientation. This was done to determine the potential for the development of entrepreneurial engineering amongst the engineering population. The results were used in conjunction with a literature review and case studies and a model was developed which engineering graduates could use to formally plan their future career paths towards managing their own businesses as entrepreneurial engineers.

The results indicated that more than $50 \%$ of the engineers correlated strongly with the various requirements necessary for successful entrepreneurship. The study that was conducted among the four engineers already in an entrepreneurial career, coupled to a study conducted by the IEEE among similar individuals provides valuable insight into the problems that are encountered by entrepreneurial engineers during the initial stages of their careers in entrepreneurship. The study is important in that it identifies the potential for entrepreneurial engineering, the pitfalls of such a career and the benefits of such a career for the individual and society. The study concludes by suggesting a mechanism whereby such entrepreneurial engineering development may be realised.
\end{abstract}

\section{INTRODUCTION}

South Africa is very similar to many developing and developed nations today that are experiencing a huge demand for engineers as countries compete for technological innovation and development [1][3]. This demand has been exacerbated by South Africa's emergence and integration into global commerce in the post-apartheid era [4]. This integration has also seen an acceleration in economic growth and development, expansion of local businesses, and expansion of the national infrastructure. Such developments have resulted in a surge in industry's demand for engineers to spearhead the "renaissance of industrialisation" of Southern Africa [1].

Since the demand for engineers comes primarily from industry, most graduates find employment within the corporate sector. However, the macro-economic implications of encouraging engineers who have acquired sufficient work experience to start-up their own businesses, termed entrepreneurial engineering, include the following: increasing self-reliance locally, increased exports (and less imports) of goods and services, increased technological innovation, economic growth, job creation, wealth creation and globalisation [2]. Entrepreneurial engineering activity has the potential to accelerate business development, increase competition, technological innovation and social development, and provide greater financial reward and self-determination for the engineering individual. This paper discusses how this may be achieved. 


\section{THE SUPPLY AND DEMAND OF ENGINEERS}

A study conducted by the Federation of Societies of Professional Engineers[4], indicates that the supply of engineers (engineering resource) in South Africa is directly proportional to the growth in population and the number of graduate engineers entering industry. The study also shows that the demand for engineers has been proportional to the business cycle and economic growth. Statistical analysis indicates a consistent shortfall (1975-1989) in the engineering resource, with the number of vacancies in a business cycle peak approaching double the available resource [4][8]. Thus, South Africa needs to more than double its output of engineering graduates over the next 20 years if it hopes to succeed economically [1]. The following are likely effects of this shortfall in engineering graduates on entrepreneurial engineering : (i) engineering graduates will continue to be absorbed by industry; (ii) job security and higher salaries (as a result of supply and demand factors) will hinder engineers from taking the risk of embarking on an entrepreneurial career; (iii) there will be a polarisation of engineering skills to the specific industries that can afford the engineering resource, which inevitably hinders the diversification of goods and services that are produced; (iv) entrepreneurial engineering skills and efforts will be concentrated in existing organisational structures.

The increase in the supply of engineering graduates and the conscious decision by engineers to plan toward an entrepreneurial engineering career are regarded as necessary steps toward achieving some of the benefits outlined earlier. This will serve as context for the rest of the material presented in this article.

\section{EVALUATING EXISTING ENTREPRENEURIAL ENGINEERS}

The results of the field research [9] that was conducted on a limited sample of engineers who have successfully started up their own businesses indicated the following: (i) most of the engineers worked in industry for a number of years in order to develop a secure skill set, whereupon they embarked on an entrepreneurial engineering career; (ii) working in industry and people-networking is regarded as a primary factor contributing to success; (iii) when planning to start up the engineers evaluated their strengths and weaknesses as well as their potential to make decisions; (iv) the nature of business of all the participants was influenced by their engineering field of study and the work experience derived in industry; (v) all the engineers created a conceptual or detailed business plan prior to starting up the business; (vi) the respondents identified the importance of basic understanding in the fields of business management, financial management, personnel management, accounting and labour law in running a business successfully; (vii) all candidates were goal orientated; (viii) candidates recommended a focus firstly on studies, followed by adequate work experience and then followed by setting up an own engineering business venture; (ix) the respondents identified inadequate experience in market strategy, personnel management, and a lack of outside consultation as hindrances to entrepreneurial success; (x) all engineers approached the aspect of risk by quantification and management, with most decisions being based on information; (xi) most candidates sought outside help when starting up their new business ventures; (xii) the entrepreneurial engineers are still involved in engineering, together with the management tasks of their businesses; (xiii) most of the entrepreneurial engineers advocated a consultative management approach with employees; (xiv) respondents identified an entrepreneurial engineering career as initially taxing on family life, and highly dependent on time management - the business in most cases was regarded as having greater priority than family. 


\section{EVALUATING THE ENTREPRENEURIAL POTENTIAL OF ENGINEERS WORKING IN THE CORPORATE SECTOR}

A total of eleven corporate engineers were surveyed (five engineers from Eskom and six from Transnet (Transtel) Ltd.) via a questionnaire. The questionnaire aimed to assess the entrepreneurial potential of the candidates based on a specific set of characteristics required for successful entrepreneurship as discussed in literature [5][6]. The results of the questionnaire [9] indicate that more than 50 percent of the corporate engineering individuals surveyed possess a readiness to enter an entrepreneurial engineering career. Figure 1 illustrates the results of the questionnaire for evaluating the criteria of: (a) competitiveness, (b) attitude towards work, (c) desire to succeed, (d) goal orientation, (e) optimism, (f) risk potential, (g) stress management, (h) creativity and innovativeness, (i) identifying opportunities, (j) positive self-attitude, (k) tendency toward entrepreneurial career, (l) effective time management $(\mathrm{m})$ desire for independence $(\mathrm{n})$ confidence in skill set.

\section{Entrepreneurial Engineering Potential}

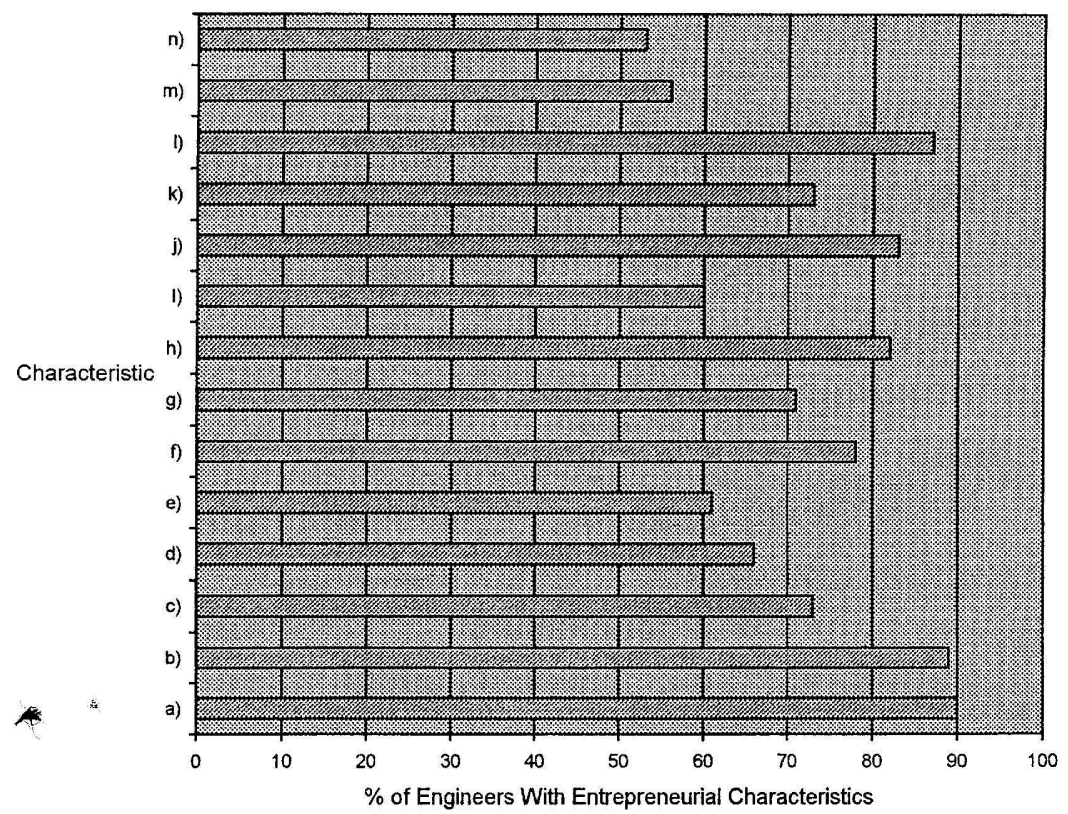

Figure 1 : Entrepreneurial characteristics profile of corporate engineering candidates [9]. 
Based on the results obtained from the limited survey conducted on entrepreneurial engineers and corporate engineers respectively (as discussed), the model shown in figure 2 has been developed [9].

The model shown in figure 2 is proposed as a development path whereby the individual (engineer) may progress toward an entrepreneurial career, that is based on the characteristics and environmental factors necessary for success as identified in literature and field studies [7], [9].

It is aimed to incorporate the major input factors that contribute toward successful entrepreneurship. Taking the engineering qualification as the point of departure, the development process is categorised into internal development and external development processes.

Internal development refers to the input factors that determine the individual's personal characteristics, attitude, motivation, education, skills and experience.

External development concerns the external factors that directly impact on the success of the entrepreneurial activity.

The model should be interpreted as follows:

1. Upon graduation as an engineer, the individual has to identify the desire to pursue an entrepreneurial career. This decision is unique to every individual; the desire to pursue an entrepreneurial career could stem from the desire for independence, control of one's destiny, or one of the other factors discussed earlier.

2. Once the desire has been identified, it is necessary for the individual to conduct an analysis based on a model such as the one proposed by Kierluff in Kroon [5], which tests the traits and characteristics of the individual as a measure of the potential for entrepreneurial success. The outcome of this test should highlight any shortcoming in the characteristics of the individual compared with the theoretical characterisation of an entrepreneur. The individual may then act on this information to evaluate and reduce possible weaknesses.

3. Once the basic personal characteristics and traits required have been assessed, one should then seek work within industry with the objective of obtaining experience, market intelligence and building contacts.

4. In conjunction with (3) above, the engineer should actively seek to enhance his or her set of skills, and identify a specific field that the individual has particular interest in; that he or she enjoys and is challenged by.

5. Once the specific field has been identified, the individual should aim to maximise his or her academic and experiential education in this field, making him or her a specialist in the identified field.

6. In parallel to the internal development, it is necessary for the individual to actively seek out to develop and enhance his or her creativity, and attempt to solve problems via innovation.

7. The engineer should also become aware of market trends, market demand/needs and learn to identify opportunities readily. Such identification is enhanced by work experience, market exposure, contacts and heightened creative and innovative potential. 


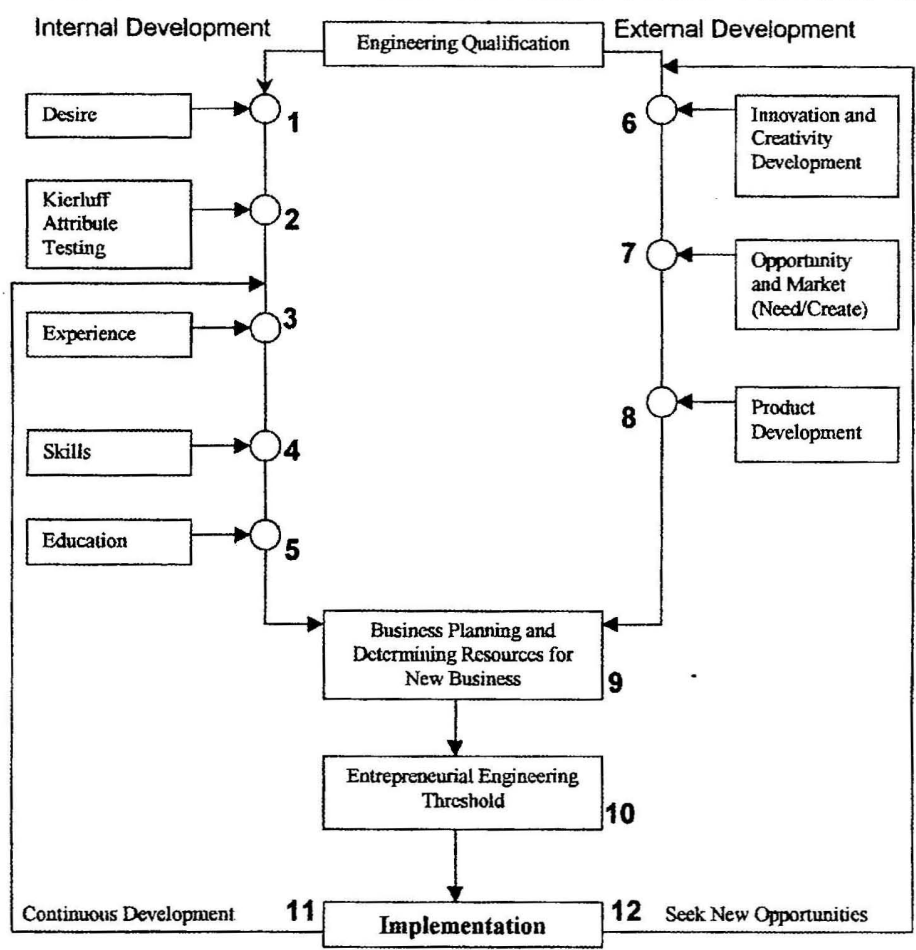

Figure 2: Model for Entrepreneurial Engineering Development [9]

8. Once a market/need has been identified, the engineer can then proceed to develop a product that meets the need. The individual should be sensitive to both the engineering and business related factors influencing the product design. These include price competitiveness, time to market, competitors' products, needs, value, features etc.

9. At this point the individual should anticipate entrepreneurial success, having reached the end of the internal ând external development processes. It is now necessary for the individual to quantify the business issues pertaining to the manufacture of the design for the identified market. This quantification process should be in the form of a business plan, which incorporates every aspect of the business, including the source of finance, labour and skills for the business.

10. Once the business plan has been generated, the individual is now on the entrepreneurial engineering threshold. The engineer has the personal skills to succeed; he or she has identified a market for a specific product; he or she has developed the product; he or she has conceptualised a business plan to deliver the product to the market. It is now necessary for the engineer to take the risk attached with starting up the new business, based on the knowledge obtained from the internal and external development processes and the business plan. Once this risk has been accepted and the engineer has decided to implement the business plan, then the entrepreneurial engineering 
threshold has been overcome and the engineer is now considered an entrepreneurial engineer. The success or failure will be determined by the market's response to the product and the success of the business plan.

11. Upon implementation of the business plan and the resulting success or failure thereof, it is necessary for the individual to continue to upgrade his or her skills, experience and education in order to maintain his or her speciality and incorporate newer developments into his or her existing pool of knowledge.

12. It is also necessary to continue to develop the external creative and innovative processes, and seek out markets, opportunities and products in order to ensure the survival and growth of the business. At this stage, the above model becomes a "life cycle" for entrepreneurial engineering activity.

\section{CONCLUSION}

In conclusion, entrepreneurial engineering is suggested as a career that should be payed serious consideration due to its broad macro-economic implications. The development of an entrepreneurial engineering "culture" within the engineering community will contribute to job creation, personal wealth creation and financial independence, increased competition, increased creativity and innovation, greater national self-reliance on products and services (and hence increased immunity to economic variations associated with importing these) and a greater potential to compete globally.

This "culture" may be achieved through the marketing of this concept, the development of entrepreneurial education within the academic curricula of engineering programs, the initiative of government and engineering bodies to develop entrepreneurial engineering within the science and technology areas (e.g. by holding workshops and seminars that train and develop this culture) and finally, by the decision to embark on an entrepreneurial engineering career by the individual engineer.

The limited research survey conducted on some entrepreneurial engineers has showed competitiveness, positive attitude towards work and effective time management skills as being especially noteworthy entrepreneurial characteristics of these engineers.

The identification of entrepreneurial engineering characteristics has led to the proposal of a useful structured approach to career path development for entrepreneurial engineers.

\section{REFERENCES}

[1] Frost Sarah, 1997. More Science Graduates Needed. Independent Educational Media, Independent Online. http://www.inc.co.za/online/hero/june 09/science.html

[2] Barnardt Nick, 1992. Understanding the South African Macro-Economy; J.L van Schaik (Pty) Ltd.

[3] Government Green Paper on Science, Engineering and Technology. 1996.

http://wn.apc.org/technology/stgreen

[4] Lloyd P J D, 1986. The Supply and Demand For Engineers, The Federation of Societies of Professional Engineers (South Africa). 
[5] Kroon J, and Moolman P L, 1992 .Entrepreneurship, Central Publications - Potchefstroom.

[6] Dyer W Gibb, 1992. The Entrepreneurial Experience. Jessey-Bass Publishers.

[7] Geppert Linda, Entrepreneurial Women Engineers, IEEE Spectrum, August 1996.

[8] Stals, C L, South African Reserve Bank Governor's Address - The Seventy-Seventh Ordinary General Meeting Of Shareholders Of The Bank. 26 August 1997. http://www.resbank.co.za/Address/annual/add97.html

[9] Khota Irfaan, July 1998. Managerial Aspects of the Entrepreneurial Engineer, Dissertation. Rand Afrikaans University. 